\title{
VARIAÇÕES SOBRE OS EQUÍVOCOS DO DEBATE DO CÂNONE
}

\author{
Fabio Akcelrud Durão \\ fabio@iel.unicamp.br
}

\section{O cânone como lugar comum}

Seria interessante algum dia investigar a fundo o processo de estabelecimento e cristalização dos lugares comuns acadêmicos, aquelas ideias que são aceitas por todos na universidade, e que passam a gozar de uma transparência e obviedade que as tornam difíceis de ser criticadas. É como a dialética da carta roubada de Edgar Allan Poe (1984, pp. 680-698.), porém mais dinâmica do que no conto do autor americano: justamente por serem repetidas ad nauseam, por ocuparem o lugar de pressuposto para diversas matrizes produtoras de argumentos, os lugares comuns acadêmicos acabam tornando-se invisíveis. Este pequeno ensaio pretende lidar com um dos lugares comuns mais marcantes nos estudos literários

${ }^{1}$ Gostaria aqui de fornecer três exemplos de tentativas que procuram romper com tais lugares comuns. Duas são minhas, e lidam com os conceitos de "texto" e com a teoria de Bakhtin: "Do Texto à Obra", in Alea: Estudos Neolatinos (Rio de Janeiro), v. 13, p. 67-81, 2011, reimpresso em Antônio A.S. Zuin; Luiz A. Calmon N. Lastória; Luiz Roberto Gomes [Orgs.] Teoria crítica e formação cultural. (Campinas: Autores Associados, 2012), p. 219-238; e "Monologismo de lo Multiple", in Tópicos del Seminario (Universidade de Puebla, México), v. 21, p. 25-46, 2009, trad. César González Ochoa. A outra, extremamente eloquente, é de Robert Hullot-Kentor, que desmitifica o ensaio de Walter Benjamin, "A Obra de Arte na Época de Sua Reprodutibilidade Técnica". Cf. "O que é reprodução mecânica”, in Remate de Males (Campinas) 29(1) - jan./jun. 2009, p. 9-23, trad. Tauan Tinti. 
de hoje, a saber, o conceito de cânone como entidade repressora. ${ }^{1}$ A intenção é mostrar que a questão do cânone literário, da forma como é normalmente articulada, tanto no Brasil como no exterior, é um falso problema; é um parafuso girando em falso, por assim dizer, com pouca ou nenhuma substância. E como são equivocados os próprios termos nos quais se coloca o debate, não apenas os denunciadores do cânone, como também seus defensores, encontram-se em erro. Porém simplesmente apontar o engano não é tão interessante quanto investigar sua necessidade. Mais do que um mero deslize conceitual ou cegueira coletiva, a polêmica em torno do cânone pode ser interpretada como um sintoma de crise tanto da cultura quanto do sistema social a que está ligada. Para ambas as esferas a noção de cânone desempenha um papel determinado, e que não é nada contestador.

\section{DESVALORIZAÇÃO DO VALOR}

O núcleo da crítica não é difícil de resumir. Em sua origem grega, kanon significava "regra" ou "padrão", "lista" ou "catálogo". Como conceito, o "cânone" surge em um contexto religioso, como a lista de livros que compõem a Bíblia judaico-cristã, e que possui uma autoridade inquestionável porque diretamente "inspirada por Deus ou legitimada por uma comunidade crente”. O uso secular do termo na crítica literária aplicar-se-ia assim "a. às regras da crítica; b. ao conjunto de obras de um dado autor; c. à lista de textos que se crê serem centrais ou 'clássicos'." (Verbete "Canon". In: The Princeton Encyclopedia of Poetry and Poetics, 1993, p. 166.) É esse último sentido que deveria ser questionado, uma vez que aqui não haveria uma instância análoga à divina que justificasse a eleição desses e não de outros escritos. Como um conjunto de obras selecionadas do universo extremamente abrangente da literatura universal o que define o cânone, portanto, é seu caráter necessariamente restritivo. Cânone e exclusão implicam-se mutualmente.

No entanto, seria enganoso desenhar uma história intelectual do termo como algo linear e progressivo. Embora sem dúvida fosse possível invocar inúmeros autores antigos que teriam de uma forma ou de outra contribuído para a elaboração de um cânone ocidental (com efeito, no limite, o termo confunde-se com a própria noção de tradição), a representação que temos hoje do conceito construiu-se a partir da década de 6o. Foi somente desde então que a questão do valor, passou a ser substituída pela do poder. É importante perceber aqui que essas duas noções não figuram isoladamente no discurso da teoria literária, mas pelo 
contrário, encontram-se interligadas. A primazia do poder reconfigura internamente o valor, pois como este anteriormente não tinha sua existência posta em questão podia simplesmente existir, sem necessitar de grandes elaborações conceituais. Se até o século XIX o valor não precisava justificar-se como tal, isso ocorria, por um lado, porque o conceito de literatura era muito mais amplo e abarcava o conjunto das belles lettres; por outro, porque a oposição básica não era exatamente entre o bom e o ruim, mas entre o refinado, polido, educado e o bárbaro, o grosseiro, o sem sentido. Em suma, ao invés de uma escala quantitativa (mais ou menos valor), vigorava muito mais o eixo de algo versus nada. Foi com o romantismo que apareceu o conceito de obra que nos é mais familiar, algo fechado em si mesmo e expressando uma experiência subjetiva digna de nota; para usar uma expressão famosa, não mais um espelho, mas uma lâmpada (ABRAMS, 1971). Essa individualização crescente do objeto - que, é claro, rearticula o conceito de literatura -, permite que surja, potencialmente, uma tensão vis-à-vis parâmetros universalistas de julgamento, o que confere maior relevo para a questão do valor.

$\mathrm{O}$ que acontece hoje é diferente, pois o valor torna-se uma categoria suspeita a priori. Isso se dá porque ele passa por um processo de desprendimento de qualquer componente que lhe seja exterior. Como algo cada vez mais imanente a si mesmo (um perfeito exemplo da lógica da dialética do esclarecimento) (HORKHEIMER; ADORNO, 1985.), o valor é tido como um construto, algo forjado histórica e socialmente em condições específicas e concretas; além disso, todavia, justamente por não encontra instância alguma que lhe valide, o valor adentra o campo semântico da guerra e passa a confundir-se com questões e tática e estratégia. Doravante, os chamados autores canônicos serão encarados como instrumentos de dominação de toda espécie - de classe (a burguesa sobre o proletariado), de raça (a branca sobre todas as outras), gênero sexual (o masculino sobre o feminino), sexualidade (a heterossexual sobre a homo e a trans), geopolítica (o Primeiro Mundo sobre o Terceiro), colonial (o Ocidente sobre o Oriente), nacional (as capitais sobre as províncias), semiótica (o significado sobre o significante), psíquica (o consciente sobre o inconsciente). $O$ fato de que a lista poderia ser estendida ainda mais sugere que está em jogo, ao invés de conteúdos específicos, algo de estrutural.

Seja como for, para contra-atacar a opressão, começa a fazer sentido lutar por espaço para as vozes apagadas e suprimidas. Porém como tal supressão não ocorre novácuo, mas em ambientes institucionais específicos; como não pode haver cânone sem instituição (embora seja plenamente imaginável uma instituição sem cânone); como as instituições, enquanto aparelhos ideológicos do Estado (ALTHUSSER, 1985.), subjetivizam os 
indivíduos; como a universidade é componente importante na reprodução da sociedade (ALTHUSSER, 1995.) - dadas essas premissas, basta somente então que se invoque um conceito deturpado de hegemonia, de Gramsci (Cf. o esclarecedor artigo de Marcos Del Roio, "Gramsci e a Emancipação do Subalterno", 2007, p. 63-78.), para que esteja montado o palco sobre o qual ocorre a guerra do cânone. A todos os atores, entretanto, parece escapar o essencial: que o objeto da contenda, o valor, é algo que não mais existe. Socialmente, é algo sem valor.

\section{TEORIA CANONIZADA}

De uma forma ou de outra, a crítica ao cânone é parte central do atual discurso da Teoria, essa nova formação discursiva que nos Estados Unidos vem suplantando aquilo que até há pouco se chamava teoria literária (Cf. meu Teoria (literária) americana, 2011.). Como já aludido acima, para cada relação de opressão há um sistema conceitual que a analisa e desbanca. Do pioneiro e influente trabalho de Richard Ohmann (Cf.e.g. "The Shaping of a Canon”, 1987.), passando pelo pós-estruturalismo, o feminismo e os Black Studies, até os Estudos Culturais, a crítica pós-colonial e a queer, o ataque ao cânone (em um deslize conceitual cada vez mais associado ao normativo) age como um denominador comum a uma séria de correntes teóricas que de outra maneira teriam muito pouco que compartilhar. Discursivamente, portanto, cânone funciona como um antagonista privilegiado, que em certa medida é condição de possibilidade da articulação centro versus margem. Note-se, contudo, a ironia patente: críticos das mais diversas linhagens defendem a inclusão de novas vozes em nome de um princípio de diferença. No entanto, a perspectiva teórica a partir da qual isso é feito é extremamente limitada e dificilmente será possível prescindir de Derrida e Foucault, ou, mais perifericamente, Deleuze, Agamben e Žižek. Ou seja, a crítica ao cânone literário encontra-se ela mesma amparada em um cânone teórico, muito mais restrito e inescapável que ele, que pelo menos tem vários séculos atrás de si.

\section{AMARRAS DO CÂNONE, CONTRA OU A FAVOR}

Porém aqueles que defendem o cânone literário tampouco têm razão. O argumento aparentemente faz sentido: devido ao tempo necessariamente limitado da vida dos indivíduos, é necessário ter cuidado com aquilo que se lê. Dada a avalanche de porcaria que a indústria cultural produz contínua e 
ininterruptamente; dado que muito da socialização dos indivíduos ocorre em torno dessas narrativas espetacularizadas (a novela, o futebol, o último blockbuster de Hollywood e o último best-seller), uma falta de esforço consciente levaria facilmente à perda de preciosos anos de leitura. Há no entanto outros fatores que merecem consideração. O primeiro é o de que o tempo de leitura não é tão exíguo assim; ele é mais do que suficiente para que alguém torne-se culto e instruído. ${ }^{2}$ Além disso, a posição daqueles que são favoráveis ao cânone pressupõe que o ruim não possa ocasionalmente ser interessante, o que não é verdade. A história da crítica literária está repleta de exemplos de comentários e análises muito superiores a seus objetos (como o Trauerspeil, para Benjamin, ou "Gradiva" para Freud) (Cf. BENJAMIN, A Origem do Drama Trágico Alemão, 2011; FREUD, Der Wahn und die Träume in $W$. Jensens 'Gradiva', 2009), e mesmo o estritamente pavoroso pode ser produtivo, como no caso do camp (Cf. SONTAG, "Notes on camp", 2009. Para uma interessante aplicação ao cinema. LEITE, "Pink Flamingos e a Gênese do Camp Cinematográfico", 2012.).

Mais importante, no entanto, é observar que a postura pró-cânone, geralmente conservadora, é forçada a pressupor que as grandes obras possuem um conteúdo que as possibilita de alguma forma figurarem na lista das mais valorosas. Para dizer com outras palavras, o conceito de cânone já prevê formalmente que os monumentos literários do Ocidente contenham atributos, predicados que lhes possam ser conferidos, enquanto o que faz tais artefatos serem dignos de leitura é justamente sua capacidade de gerarem predicados - ou, melhor, talvez, de negarem a predicação (Cf. meu Modernism and Coherence: Four Chapters of a Negative Aesthetics, 2008; trad. bras. Modernismo e Coerência: Quatro Capítulos de uma Estética Negativa, 2012.). Uma preocupação com o cânone incentiva uma identificação de características, temas, assuntos, ao passo que o verdadeiramente interessante é relacionar-se com as obras por meio de questões que em última instância as modificam por dentro. Digase de passagem, isso ajuda a explicar o enfraquecimento das produção crítica mais recente de Harold Bloom, como O Cânone Ocidental (1994), em relação ao começo de sua carreira, em A Angústia da Influência (1973)

${ }^{2}$ Fiz o seguinte cálculo: assuma-se uma semana de 40 horas de trabalho e um ano com 48 semanas (total 1.920 horas anuais); considere-se uma vida produtiva de 65 anos (dos 15 aos 80 , por exemplo - total 125.800 horas); agora imagine-se um ritmo de 10 páginas por hora (total 1.258.ooo páginas), e uma média de 200 páginas por volume. $O$ total de livros que se pode ler em uma vida é de 6.290. Está certo que essas são condições extremamente favoráveis; no entanto, a massa textual que comporta é superior àquilo que quase qualquer grande escritor jamais leu, incluindo Marx, Freud, Nietzsche, Shakespeare, Goethe ou Machado de Assis. 
ou Wallace Stevens: The Poems of Our Climate (1977), por exemplo. Ao acompanhar esse percurso é possível perceber que as obras literárias vão tornando-se cada vez mais idênticas a si mesmas.

O estágio último de empobrecimento é atingido quando o adjetivo "canônico" torna-se pesado, seja positiva, seja negativamente. Assim como no caso de "cultura erudita", o seu emprego já corresponde a um distanciamento daquilo que seria a experiência estética do artefato. Em outras palavras, o "canônico" já é um conteúdo que se interpõe àquele difícil ideal hermenêutico de tentar fazer o texto virar o sujeito e o leitor o objeto pelo qual ele fala, ou seja, o ideal de não trazer nada para o confronto com a obra, de fingir a ingenuidade, ou de lembrar-se de esquecer (Vem daí o interesse metodológico do livro de Daniel Heller-Roazen, Ecolalias, 2011). Nesse sentido, o cânone funciona como uma espécie de pré-organização de sentido; ele participa, no fundo, da lógica da indústria cultural, que ora confere aos objetos da chamada alta cultura toda a dignidade e reverência, porque isso vende, ora os ataca como elitista em prol de outros, porque isso também vende. $\mathrm{O}$ conceito de grande obra é precário e dinâmico. Se ela deixa de ter algo de novo a dizer, ela simplesmente morre - e a crítica não deixa de ser um agente disso. Não há garantia alguma para que Shakespeare seja considerado um grande autor; pelo contrário, é uma questão de fato urgente saber se seus textos podem sobreviver à superexposição à qual vem sendo submetidos. Se você se deixa afetar pelo "canônico" do que lê, seja positiva ou negativamente, faz pouca diferença ter 10 ou 50 anos à sua disposição.

\section{UM POUCO DE REALIDADE}

A opressão que se identifica no cânone é imaginária e não se sustenta empiricamente. É produtivo aqui comparar a revolta americana, que é crítica e ocorreu há sessenta anos, com a francesa, que foi literária e deuse bem antes, pelo menos com as vanguardas do começo do século XX, senão com Baudelaire. Nos Estados Unidos não existe uma Academie Française, que determina quais palavras existem e quais não entrarão no dicionário; nunca houve uma instância centralizadora, como um Ministério da Educação interventor, que determinasse o que deveria ser lido nas universidades. E mesmo que no segundo grau haja listas de livros, isso é muito distante da censura ou mesmo da indisponibilidade de obras. Aquele que seria o autor central do cânone anglófono, Shakespeare, foi inúmeras vezes atacado por críticos de pendor classicista por não respeitar as unidades aristotélicas, por não acatar o decoro linguístico e inundar 
seus escritos com linguagem obscena, e por misturar estilos, o que muitas vezes denotava uma ojeriza ao popular por parte de seus detratores.

No Brasil, dada a fragilidade das instituições em todo o âmbito da cultural, a suposta dominação de um cânone é ainda mais irreal. É só pensar na precariedade de nossas bibliotecas, ou na ausência de um conceito normativo de universidade na maior parte das unidades de ensino superior no Brasil (que são vistas, seja como escolões, seja como lugares para se aproveitar verbas do Estado), para que se desfaça a autoridade do conceito de autoridade. Nem mesmo Machado de Assis, a figura central do que seria o cânone brasileiro, possui uma edição definitiva de suas obras completas, que inclua todas as suas crônicas e escritos de jornal. O estado de saturação comum aos grandes autores - ele sim uma grande ameaça à sua vida e relevância -, aquela superprodução bibliográfica que faz com que um Proust, Kafka, Dante, Homero ou Cervantes tornemse quase ilegíveis é praticamente inexistente no Brasil, ocorrendo talvez para Machado de Assis e Guimarães Rosa apenas. As únicas ocasiões nas quais faz algum sentido falar de cânone são nas compras governamentais para as escolas públicas e a lista do vestibular, realizada por professores universitários, nossos colegas.

Com efeito, a fragilidade das instituições culturais nacionais não consegue escapar do ridículo, como no episódio de outorga, em 2011, da medalha Machado de Assis da Academia Brasileira de Letras a Ronaldinho Gaúcho e Wanderlei Luxemburgo. A ideia aqui era prestigiar o Flamengo como um importante agente da cultura popular brasileira (a presidente do clube também recebeu uma distinção, menor, na ocasião). O cômico, neste caso, reside tanto na incongruência quase surrealista entre o jogador e o técnico, por um lado, e o mundo letrado, por outro, quanto no fato de que alguns meses depois nem jogador, nem técnico pertenciam mais ao time. Esse acontecimento grotesco é saudável para mostrar a subserviência e falta de qualquer brio dos chamados eruditos, no Brasil, vis-à-vis àquilo que se denomina cultura popular, mas que, no caso do futebol, não é senão um conglomerado de empresas com transparência mínima, um dos menos democráticos e responsáveis da sociedade. Diante do poder da indústria cultural, que abarca também a alta cultura, o poder desta última é uma piada.

A fragilidade do mundo das letras é fruto de sua absoluta falta de relevância social, que também é sua força. Discutir literatura é um luxo; como algo supérfluo, que não se relaciona com as instâncias reais de poder permite o exercício de uma liberdade de pensamento inconcebível em outros contextos. Falar de opressão, de estratégias de silenciamento, de luta por hegemonia soa ligeiramente cômico quando se pensa no quão 
diminuto é o objeto de disputa. Não há mediação possível do campus para a Revolução. Em vista disso, justamente por causa da liberdade de que goza, a militância anti-canônica acaba tendo o efeito de uma self-fufiling profecy, um vaticínio de não-liberdade que concretiza aquilo que propõe. Se é para falar de política das Letras, mais importante do que condenar a suposta opressão de Shakespeare, Joyce ou Clarice Lispector seria atentar para o fato de que o campo dos estudos literários como um todo só existe devido a uma espécie de boa vontade política para com as instituições universitárias existentes, sem dúvida motivada pelo baixo custo de sua manutenção. Para repetir o que foi dito acima, diante do processo de modernização capitalista, da transformação de tudo em mercadoria, a existência dos cursos de Letras públicos e gratuitos com uma presença generosa da literatura é algo defasado e precário. Não seria difícil imaginar uma situação na qual a universidade pública fosse reestruturada e que com isso se abolisse ou dissolvesse o estudo da literatura - algo que já está acontecendo no segundo grau. Por isso talvez fosse mais produtivo virar o problema de cabeça para baixo e identificar nessa postura beligerante uma construção fictícia que outorga grandes poderes para os professor universitário, como se ele estivesse no centro de um redemoinho cultural, como se suas posturas e atitudes fossem decisivas para a manutenção ou desestruturação do status quo. Isso é um mecanismo de compensação, na melhor das hipóteses, e mania de grandeza ou má-fé, na pior.

A ideia de um cânone sufocante, organizado para vangloriar escritores homens, brancos e ocidentais, projeta uma imagem de autoritarismo que é falsa. Ela pressupõe aquilo que Guy Debord já há bastante tempo chamou de espetáculo concentrado (A Sociedade do Espetáculo, 1997), uma centralização extrema na produção de signos, o justo avesso do regime de superprodução semiótica que marca o nosso cotidiano. Com um pouco de imaginação é possível trazer a mente o que seria uma situação de opressão real, que envolvesse a prescrição de determinados textos e a proibição de outros; que normatizasse plenamente o ensino, obrigando a leitura das mesmas obras; que controlasse o sentido dos chamados clássicos; que monopolizasse a outorga de prêmios literários; que manipulasse as associações de escritores; que fechasse editoras; que regulasse as gráficas; que dispusesse dos jornais. Uma amiga romena ofereceu-me uma imagem forte disso ao descrever o triste sentimento de vazio por que passou após a destituição e execução de Nicolae Ceaușescu, a quem odiava. As repulsivas imagens e a voz do ditador de alguma maneira faziam companhia; sua ausência atestava a ubiquidade do corpo do tirano e como ele funcionava como um núcleo para a produção social de signos. Ainda que a crescente concentração de poder dos 
grandes conglomerados empresariais da cultura pudesse sugerir algo de semelhante, o funcionamento básico dos dois regimes sígnicos, o difuso e o concentrado, é bem diferenciado. Sob nosso regime de produção de linguagem nem mesmo o ultraje se alcança com facilidade. Veja-se o caso de Pornopopéia (2011), de Reinaldo Moraes: ao invés de ser banido ou ao menos ser vendido às escondidas na livras, já tem edição de bolso. Seria mais pertinente observar que a contestação é hoje necessária para a manutenção das relações de poder. Através dela preserva-se a aparência da liberdade e descarta-se as mercadorias produzidas antes de ontem. A revolução é um termo que pode aparecer em praticamente qualquer comercial.

\section{UM SISTEMA SEM CENTRO}

O caráter irreal da dominação do cânone possui uma necessidade social mais ampla; com efeito, o que apoia a própria formação do conceito de cânone - e, mais importante, claro, a sua contestação - está em harmonia com a transformação da cultura no capitalismo globalizado. Em seu interessante livro The University in Ruins (1997), Bill Readings postula que, no mundo transnacional de hoje, a universidade deixou de ter a missão de alastrar a Razão, como no século XVIII, ou de promover a cultura nacional, como no XIX. Ela é agora regida por um imperativo de excelência, o que significa que ela não mais é medida por algum parâmetro exterior, mas tão-somente pela comparação entre instituições. Uma universidade excelente não é aquela que realiza uma tarefa específica, mas que a realiza melhor. Isso ilumina o funcionamento da cultura como um todo neste começo de século XXI. Totalmente profissionalizada, industrializada e mercadorizada; totalmente desprovida de um horizonte utópico que lhe conferisse alguma negatividade, a cultura pós-moderna tornou-se o local da mediação universal, da possibilidade de conexão de tudo com tudo. É interessante notar como isso se manifesta em relação aos grandes autores, cujos textos surgem com campos de sentido nos quais qualquer coisa pode significar. A cultura perde assim o seu outro e a própria alteridade converte-se em um tópico predileto. A causa e consequência disso é a irrepresentabilidade de qualquer noção de centro, e uma das passagens mais iluminadoras do livro de Readings é aquela na qual observa que mesmo os pensadores de direita norte-americanos como Allan Bloom (1987) ou John M. Ellis (1999) (ou o Luiz Felipe Pondé, ainda que bastante inferior a eles) precisam argumentar que estão excluídos, para que suas ideias possam sequer almejar a ter algum apelo ou validade 
aparente. Como já indicado acima, o cânone literário desempenha um papel discursivo preciso, o de permitir a defesa de algo que lhe seja contrário, que por ele estaria sendo cerceado, ignorado ou suprimido - e, de novo, diante da perda de especificidade da cultura esse gesto tornouse necessário para que qualquer argumento possa ser sustentado. A identidade defensora da crítica ao cânone está assim adaptada tanto para o funcionamento da universidade produtivista quanto para a sociedade em seu sentido mais amplo - uma sociedade, é claro, com amplas fissuras, na qual ainda é plenamente possível chamar a atenção para os equívocos do debate do cânone.

\section{REFERÊNCIAS BIBLIOGRÁFICAS}

ABRAMS, M. H. The Mirror and the Lamp: Romantic Theory and the Critical Tradition. Oxford: O.U.P., 1971 [1953].

ALTHUSSER, Louis. Aparelhos Ideológicos do Estado. Tradução Walter André Evangelista e Maria Laura Viveiro de Castro. $3^{\mathrm{a}}$ ed. Rio de Janeiro: Graal, 1985 [1970].

ALTHUSSER, Louis. Sur la réproduction. Paris: P. U.F., 1995.

BENJAMIN, Walter. A Origem do Drama Trágico Alemão. Tradução João Barrento. Belo Horizonte: Autêntica, 2011 [1928].

BLOOM, Allan. The Closing of the American Mind. Nova York: Simon \& Schuster, 1987.

BLOOM, Harold. The Anxiety of Influence: A Theory of Poetry. New York: Oxford University Press, 1973; 2 d ed., 1997.

BLOOM. Wallace Stevens: The Poems of our Climate. Ithaca, NY: Cornell University Press, 1977 .

BLOOM. The Western Canon: The Books and School of the Ages. New York: Harcourt Brace, 1994 .

DEBORD, Guy. A Sociedade do Espetáculo. Tradução Estela dos Santos Abreu. Rio de Janeiro: Contraponto, 1997 [1967].

DEL ROIO, Marcos. "Gramsci e a Emancipação do Subalterno". Revista Sociologia e Política. Curitiba: nov 2007, p. 63-78.

DURÃO, Fabio Akcelrud. Modernism and Coherence: Four Chapters of a Negative Aesthetics. Bern/Frankfurt: Peter Lang, 2008.

DURÃO, Fabio Akcelrud. Modernismo e Coerência: Quatro Capítulos de uma Estética Negativa. São Paulo: Nankin Editorial, 2012. 
DURÃO, Fabio Akcelrud. Teoria (literária) americana. Campinas, SP: Autores Associados, 2011.

ELLIS, John M. Literature Lost Literature Lost: Social Agendas and the Corruption of the Humanities. New Haven, CT: Yale University Press, 1999.

HELLER-ROAZEN, Daniel. Ecolalias. Tradução Fabio Akcelrud Durão. Campinas, SP: Editora da Unicamp, 2011 [2008].

HORKHEIMER, Max; ADORNO, T.W. Dialética do Esclarecimento. Tradução Guido Antonio de Almeida. Rio de Janeiro: Zahar, 1985 [1947].

LEITE, Pedro. "Pink Flamingos e a Gênese do Camp Cinematográfico". In: PAZ, Ravel; DURÃO, Fabio Akcelrud (Org.). A Indústria Radical: Leituras de cinema como arteinquietação. São Paulo: Nankin Editorial, 2012.

MORAES, Reinaldo. Pornopopéia. Rio de Janeiro: Objetiva, 2011 [2008].

OHMANN, Richard. “The Shaping of a Canon”. In: Politics of Letters. Middletown, CT: Wesleyan University Press, 1987.

POE, Edgar Allan. “The Purloined Letter”. In: Edgar Allan Poe: Poetry and Tales. Nova York: Library of America, 1984 [1844].

READINGS, Bill. The University in Ruins. Cambridge, MA: Harvard U.P., 1997.

SONTAG, Susan. "Notes on camp”. In: Against Interpretation and Other Essays. Londres: Penguin, 2009 [1964].

The Princeton Encyclopedia of Poetry and Poetics. Princeton: Princeton U.P., 1993. 
